\title{
Escritura cervantina en Sanco Panco: parodia y recreación del Quijote según Salvador de Madariaga
}

\author{
Alexia Dotras Bravo*
}

Salvador de Madariaga (A Coruña 1886-Locarno 1978), diplomático, historiador y escritor español, escribió una docena de novelas, trece obras de teatro y unos diez poemarios -que hayan sido publicados-, lo que lo sitúa en un puesto de autor prolífico y desconocido. Sanco Panco pertenece a la serie que Octavio Victoria Gil, su biógrafo más reputado, denomina "Novela literaria, satírica y política" (1990: 499), publicada en 1964 por la editorial Latino Americana de México.

Concebida como una parodia crítica, no solo al régimen de Franco, sino también a los líderes políticos mundiales, fue rechazada por la prensa española y bien recibida en Iberoamérica. Con un juego doble de identidades, cervantinas por un lado, y políticas contemporáneas por otro, se desarrolla una de las obras del polígrafo, nunca después reeditada. Madariaga presenta una novela claramente cervantina en su escritura, en su estilo, como el propio título asegura: La más verídica que verdadera historia de Sanco Panco. Escribiola Miguel de Corzantes y la da hoy a luz Salvador de Madariaga, haciendo un guiño nada más empezar a la técnica del manuscrito hallado, que parodia Cervantes y que ya había utilizado en La jirafa sagrada (1925). Pero también presenta una voluntad completamente contemporánea, al tratar los asuntos y personajes más relevantes de la política mundial, sin nombrarlos directamente.

Pero antes de pasar a analizar esta obra y su interesantísimo juego de identidades y rescritura cervantina, quiero manifestar la pasión que sintió Madariaga toda su vida por la obra cervantina. Quizás sea su ensayo cervantino Guía del lector del «Quijote», el más conocido, siempre presente en la crítica actual, aunque sea para desmentirlo como se ha visto en algunos trabajos de

* Universidad de Coímbra 
los últimos tiempos (Martín Morán, 1992: 75-118; Williamson, 2007: 837858; Dotras Bravo, 2008: 299-378).

No es posible en este espacio evaluar la importancia de este ensayo y su repercusión en la crítica actual, algo que ya he hecho en otra parte (Dotras Bravo, 2008), pero sí se puede recordar el abanico de estudios cervantinos, así como obras literarias inspiradas en la obra de Cervantes, que van desde los apuntes manuscritos de sus clases en Oxford (1928-1931) hasta la edición comentada del Quijote en la editorial Sudamericana (1962).

De todos ellos, dos forman parte de la faceta de creador literario, dos obras de teatro, una bastante conocida, corta, y otra, mucho más larga, todavía inédita, conservada en manuscrito y copia mecanografiada. Don Quixote and Sancho. A dramatized and abridged versio of Cervantes 'novel está compuesta por 246 páginas. Los investigadores que entre los años 1993 y 1995 pusieron en orden la inmensa cantidad de papeles de Madariaga, consideran esta obra de teatro inédita, así como otras. No tengo constancia alguna de que nadie haya publicado este escrito, por lo que permanece inédito. No está fechado aunque, por las cartas entre escritor y editor, estaba ultimándose en 1947, ya que se enmarca en los actos conmemorativos del cuarto centenario del nacimiento de Cervantes. Las conversaciones continúan en 1948, y en ellas todavía se están tomando decisiones sobre el número de escenas y correcciones varias. Probablemente, después de pasada la fecha del aniversario, la prisa por terminar el proyecto decae y quizá sea esa la razón por la que nunca se publica.

Por otra parte, se encuentran varias cartas de Madariaga a Zdenko Bruck, responsable de la Editorial Sudamericana que había mostrado interés en publicar El doce de octubre de Cervantes, en su origen pieza radiofónica, en una edición para bibliófilos. Se trataría de una edición ilustrada por Raúl Soldi, Lucio Muñoz o Pablo Picasso y la idea surgiría porque estarían trabajando en la edición ilustrada de La cruz y la bandera, y en otras ediciones de la obra del escritor.

El doce de octubre de Cervantes es una pieza dramática hipotética que recrea la vida de Cervantes; de un solo acto y escrita en prosa, con un estilo cervantino, que Madariaga demuestra dominar tanto en esta ocasión, como en la redacción de Sanco Panco. Esta emulación del lenguaje, no solo del XVII, sino también característico del Quijote, demuestra la capacidad imitativa de Madariaga, aquí de una forma seria, y en Sanco Panco con tintes cómicos. Gregorio Torres Nebrera menciona esta pieza teatral en la recopilación y análisis de todas las adaptaciones teatrales del Quijote en "Don Quijote en el teatro español del siglo XX” (1992: 93-140). Se representó en 1956 en París en la Sala Pleyel como indica Arturo Ramoneda (1986: 283).

Sorprende que en una pequeña obra de cerca de diez páginas se concentren todos los temas que ocuparon el centro del Quijote. Por un lado, Cervantes, personaje ahora, encarna el prototipo de caballero renacentista galanteador, poeta y soldado, desdichado en amores, con una angustia de vivir esencialmente filosófica (Madariaga, 1983). 
Lo interesante es comprobar que los rasgos inherentes del estudio cervantino del que parte Madariaga se encuentran en todas sus obras, críticas o de creación: la mención a Dulcinea como símbolo de gloria, la diferente percepción de la realidad de ambos personajes, la influencia mutua, los refranes y los juegos de palabras, el desdoblamiento de Cervantes en Cide Hamete Benengeli como una ficción consciente o la idea de la fama testimonian, más que las constantes que el escritor renacentista impregnó en su obra, las obsesiones que coronan los estudios cervantinos y quijotescos de Salvador de Madariaga.

Si los hitos cervantinos creativos de Salvador de Madariaga se remontan a 1947, se extienden hasta 1964 y lucen estas tres escalas: dos teatrales y una narrativa, Sanco Panco constituye el final de esos veinte años de camino, un resultado logrado con la combinación de parodia cervantina y parodia franquista.

El argumento de la obra es ciertamente complejo, teniendo en cuenta que no hay asunto claro: en un mundo arcaico, sin contextualizar, pero plagado de Gigantes y Cabezudos, un hombre, Sanco Panco, aspirante a rey de Hesperia, tiene que llevar a cabo su mandato. Ha de luchar con dos gigantes -o más bien negociar- Ursio y Usio, además de otros dos: Yantasión y Sumaleón. Cuando por fin consigue ser rey, cambia el nombre de su país: Sanquipanquia o Espanquia y modifica los suyos propios: Yomandísimo, el Adalid, el Gran Magín y decide vivir en su caverna, El Castaño Oscuro. La trama de la historia pasa por las relaciones diplomáticas entre unas potencias y otras, ya que se trata, en el fondo, de un remedo de las novelas de intriga, de relaciones políticas y acuerdos diplomáticos, todo desde el prisma de la parodia.

En sesenta pequeños capítulos, cuyos títulos son absolutamente cervantinos, desarrolla una imagen grotesca de veinte años de dictadura franquista y de las relaciones de España con Europa y América, cuyos episodios, ciertamente independientes, pero con un hilo conductor común, orden cronológico y consistencia en los personajes, eran perfectamente reconocibles por el ciudadano común de la época.

Sin embargo, la influencia de Cervantes empieza por el empleo de la técnica del manuscrito hallado, remedo a su vez de una de las estrategias de los libros de caballerías para hacerlos creíbles. Salvador de Madariaga, en primera persona, relata la llegada de un original desordenado e ilegible de un Manuel de Corzantes, que Madariaga - de lleno en el papel que quiere representar- interpreta como un seudónimo claro de Cervantes. El tono reivindicativo de las dos cartas que recibe del autor oculto tras el nombre ficticio resulta evidente, mezclado con la fórmula de tratamiento arcaica, produciendo los primeros contrastes, irónicos:

Publicad, publicad. ¡Qué más quisiera yo que poder decirlo aquí! Publicad sin tardanza. Pero que no sea posible sospechar que la obra se ha escrito aquí. Hay que inventar un autor que vive en Lima o en Helsinki o en el mismo Infierno... Bueno, eso no, que el Infierno está demasiado cerca de aquí. Ya me comprendéis (Madariaga, 1964: 9). 
El propio título, como ya he indicado, es cervantino y hace referencia al género al que adscribe Madariaga esta obra: la "novela-fantasía", por eso la titula La más verídica que verdadera historia... es decir, que constituye "una fantasía bordada sobre una realidad" (1964: 8), poniendo la primera piedra para el debate entre realidad y ficción. Por su parte, los capítulos, breves, comienzan en un porcentaje elevadísimo por la estructura clásica de los títulos: largas frases precedidas de la preposición "de", o el adverbio "donde" o conectores como "en que" más algunos datos, normalmente que fomentan la intriga, aunque aclarando los pasajes que contiene el capítulo. Destaca también por la combinación de títulos paródicos con otros exclusivamente informativos: Así, "Donde sale a escena en persona el gran Canciller" (cap. 8) convive con "Del modo cómo La Chamarilería y La Cuquería se entendieron con la Cofradía de las Almadrabas y con la Sobrinería Mayor" (cap. 24) y hasta con el más largo, donde la escritura cervantina se fusiona con la jerga popular del siglo XX: "Donde se pinta con sombríos colores una siniestra conspiración contra la felicidad de Espanquia y la estabilidad de su régimen que son dos aspectos distintos de una misma cosa verdadera y si no que venga Dios y lo vea, pero verá usted como no viene" (cap. 54).

Por otro lado, utiliza el epílogo en verso, al estilo de Cervantes, con una serie de poemas que imitan cómicamente aquellos escritos de los académicos de Argamasilla al final del Quijote de 1605, con la misma capacidad inventiva lingüística. En este caso, a partir de una palabra real "encomio" crea, por reduplicación fonética y silábica, los "Encomios, encomomios y encocoromios". Con neologismos, palabras imposibles, combinaciones léxicas ingeniosas, aderezado con su buena mano para la rima, hasta en ese aspecto Madariaga encara otros rasgos del estilo cervantino.

Por tanto, no solo el título, los capítulos, la estructura general -interna y externa-, la técnica del manuscrito hallado y los poemas satíricos que coronan la obra constituyen elementos de escritura cervantina, sino que los personajes de Sanco Panco presentan una compleja identidad doble: por un lado, las identidades contemporáneas a las obras, que necesitan un esquema y alguna interpretación atrevida, proporcionada por Octavio Victoria Gil, pero han de relacionarse, en un segundo nivel, con los posibles personajes cervantinos que, más que presentar correspondencias exactas, responden a prototipos y figuras literarias generales, excepto el propio Sanco Panco, un "Sanco Panco negativo, símbolo de la ignorancia, del rusticismo taimado, de la superstición y deseoso de medrar" (Casas de Fauces, 1981: 921).

Este Sanco Panco-Francisco Franco-Sancho Panza, el personaje con la identidad más compleja, pero también más definida, se desvía de la visión madariaguesca, pero quizás no tanto, ya que el Sancho Panza que ofrece Madariaga en sus escritos presenta ambiciones desmesuradas, toques rústicos insuperables, cobardía evidente y algún que otro defecto más (Dotras Bravo, 2008: 134-140, 194-203). En este mismo sentido, pero sin ser cervantino, destaca otro personaje propio de los libros de caballerías que enloquecieron a don Quijote, en este caso armonizado con el parecido fonético: el famoso 
gigante, Amaonze de Gaula, "que llevaba traza de dar once y raya a Amadis" (Madariaga, 1964: 232), un fantástico ser inspirado en Charles De Gaulle.

Sin embargo, la lectura de Sanco Panco no sería exitosa sin la interpretación de las identidades contemporáneas de Victoria Gil (1990: 543-545), de las que ni él mismo se fía a veces (¿será el Gran Miriálogo el presidente Azaña? ¿el senador Sinseso sería el senador J. William Fullbright? ¿algunos españoles famosos estarían representados en Juan Manuel, torero de Madroño -Luis Miguel Dominguín- y Apolonio Redropelo -Dionisio Ridruejo?). Pero incluso para los que nacimos con la Constitución, y no hemos vivido ni estudiado en nuestros planes de estudios la dictadura de Franco, algunos personajes son perfectamente identificables y especialmente ingeniosas sus equivalencias lingüísticas, porque perviven hasta la actualidad su presencia, sus ecos, o su vigencia.

Tal es el caso de Hesperia-Sanquipanquia-Espanquia para España; el Castaño Oscuro para el palacio del Pardo; Haga y Noable para Fraga Iribarne; los carasoles para los falangistas; el glorioso Trajín para el glorioso Movimiento Nacional; el conde Esperabé para el conde de Barcelona que vive en El Toril; o Ilusitania para Portugal, entre otros muchos que Victoria Gil ha identificado.

Otros, en cambio, no se perciben por sus similitudes lingüísticas, pero se aprecia el ingenio y la perspicacia por encima de otras virtudes, lo que propicia el juego cómico y la risa del lector. Como sucede con la isla Cañabana (Cuba), gobernada por Cástor (Fidel Castro) y Pólux (Raúl Castro) o Doña Urraca de las Gemas Verdes, personificada en doña Carmen Polo, o Galicia nombrada como Laconia, la base se constituye aquí en la metáfora. Pero nada más surrealista y cacofónico como los gritos de aliento militar al general Franco: “¡Franco, Franco, Franco! ¡Arriba España! ¡Una, grande y libre!” traducidos por Madariaga: “¡Taro, Taro, Taro! ¡Tarira, Tárira! ¡Tura, Tare y Títere!".

Algunos pasajes remiten a la más genuina literatura cómica, con el mismo ingrediente común, que resulta fundamental para el autor: la invención idiomática. Así, su condición de trilingüe le ayuda a construir un pasaje entre un español hablando francés, Marrano Nadasé, o Mariano Nadasar, su nombre real, y el americano Sinseso. Con mala fama aún hoy para los idiomas, Nadasé, haciendo honor a su nombre, traduce literalmente el español, plagado de expresiones hechas que llenan de confusión a Sinseso e impiden la comunicación ${ }^{1}$, provocando la hilaridad: porque en Espanquia, "les chosses marchent manche pour hombre" y el Gran Magín o Yomandísimo y el propio Nadasé son "ongle et viande" e incluso "un pé vive-la-vierge", aunque su mujer es religiosa, pero no tanto porque en Espanquia “il n'y a religión ni Christ qui l'a fondé". El Senador, completamente perdido, acabó por abandonar el camino irremediablemente porque "n'ont pas de chandelle dans cet enterrement".

Lo mismo podríamos decir de la conversación entre Sanco Panco y el conde Esperabé (1964: 140-143) en El Toril. O de la España profunda, repre- 
sentada en un pueblo imaginario, Tuestalaencina que, a modo de contrapunto literario, aparecen con sus primitivas formas de expresión política (caps. 2629, cap. 50). Y así, cada capítulo de la novela, cada historia paralela, constituyen lo mejor del humor y la ironía madariaguesca.

La novela fue recibida por la crítica y la actualidad periodística de una manera moderada, como todo aquello que hacía Madariaga, silenciado en España. Alguna reseña en inglés, como la de James. R. Browne en Books Abroad (1966: 195), destaca el absurdo, el surrealismo y la falta de intención satírica amarga. En esa línea escriben los periódicos sudamericanos, que repiten dos reseñas en varios medios, de la mano de Félix R. Anderson y Pedro Gringoire, como en Excelsior, El porvenir o el Diario Las Américas, en 1964. Con el título de "La gran carcajada" y "Los hijos de Sánchez" destacan la vena satírica, el estilo cervantino y la capacidad de crear nombres ficticios, pero transparentes.

Pero será en el diario Panorama, de Maracaibo, Venezuela, donde observaremos una reseña más severa, sin firma. Se muestra conocedor de las críticas y alaba la apariencia juvenil de la novela y la valora como el más duro golpe a la dictadura francofalangista. Llega a realizar una reflexión profunda sobre el humor como superación de un dolor o una amargura o desengaño, pero critica la sátira porque es ineficaz, cree que Madariaga tenía que haberlo hecho más abiertamente.

Octavio Victoria, en su estudio tan detallado, aún aporta las críticas de Eugenio de Nora (1968: 79-92), negativas, que sitúan la obra en un nivel panfletario y superficial o la valoración positiva de McInerney (1970), el primer investigador interesado en Madariaga y su faceta literaria.

Son muchos los elementos evidentemente cervantinos, que recojo ahora, empezando por el título, la estructura general, los capítulos y sus denominaciones, la técnica del manuscrito hallado, los epílogos en verso, la invención lingüística como base del humor o la denominación y carácter de algunos personajes, entre otros. El paseo, aparentemente sencillo, por el estilo cervantino solo se puede deber, al estudio intenso, al conocimiento detallado y a años de lecturas de las obras cervantinas y, específicamente, de Don Quijote de la Mancha. Además, la combinación con la visión contemporánea política de la época confiere a la obra cervantina una constante reactualización de sus significados, una perenne novedad en sus lecturas.

Para concluir, me sumo a la apreciación final de Octavio Victoria que, además de la influencia cervantina enfatiza la de Rabelais y que hace un llamamiento final, allá por 1990, que todavía no se ha cumplido: la de la reedición de la novela. En una época en la que vivimos la recuperación de textos olvidados del siglo XX, lo que Winston Manrique denomina efecto Big Bang en la literatura, "Escritores cuya luz literaria se ha vuelto a ver décadas después de haber creado sus obras y brillar en su momento, pero eclipsados luego por diversos factores" (5-6-2006), Salvador de Madariaga, con su Sanco Panco podría ser una grata sorpresa para todos los lectores, ya que en la recién estrenada democracia "el autor no quiso autorizar la reedición de esta 
novela, en España, para no herir susceptibilidades, buena prueba de su espíritu exquisito" (Victoria Gil, 1990: 563).

\section{BIBLIOGRAFÍA}

Browne, James R., (1966) "Review", Books Abroad. 40, Spring, p. 195.

Casas de Faunce, María, (1981). "Sancho Panza según Miguel de Corzantes" en Manuel Criado de Val (ed.), Cervantes, su obra y su mundo. Madrid: Edi-6, pp. 921-926.

Dotras Bravo, Alexia, (2008). Los trabajos cervantinos de Salvador de Madariaga. Historia de una idea doble: sanchificación y quijotización. Alcalá de Henares: Centro de Estudios Cervantinos.

Nora, Eugenio de, (1968). La novela española contemporánea. Madrid: Gredos, tomo III, pp. 79-92.

Madariaga, Salvador de, (1983). El doce de octubre de Cervantes en Salvador de Madariaga, Teatro en prosa y verso. Madrid: Espasa-Calpe.

Madariaga, Salvador de, (1964). Sanco Panco, México: Latino Americana.

Manrique, Winston, "Escritores del Big Bang", El País, 5-6-2006. También en http:// www.elpais.com/articulo/cultura/Escritores/Big/Bang/elpepicul/20060605elpepicul_2/ Tes?print $=1$ (consulta el 18.01.2013)

Martín Morán, José Manuel, (1992). "Don Quijote está sanchificado; el des-sanchificador que lo requijotice...", Bulletin Hispanique. 94, pp. 75-118.

McInerney, Francis William, (1970). The novels of Salvador de Madariaga, A dissertation presented to the Faculty of the Graduate Collegein the University of Nebrasca, Tyler.

Ramoneda, Arturo, (1986). "El teatro de Salvador de Madariaga" en Salvador de Madariaga. A Coruña: Libro Homenaje del Ayuntamiento de A Coruña, pp. 251-286.

Torres Nebrera, Gregorio,(1992). "Don Quijote en el teatro español del siglo XX", Cuadernos de teatro clásico. 7, pp. 93-140.

Victoria Gil, Octavio (1990). Vida y obra trilingüe de Salvador de Madariaga. Madrid: Fundación Ramón Areces.

Williamson, Edwin, (2007). "The Power-Struggle between Don Quixote and Sancho: four crises in the development of the narrative", Bulletin of Spanish Studies. 84, $\mathrm{n}^{\mathrm{0}} 7$, pp. 837-858.

Recibido: 6 de julio de 2012

Aceptado: 30 de octubre de 2012

\section{Resumen:}

La novela de Salvador de Madariaga Sanco Panco fue publicada en 1964 por la editorial mexicana Latino Americana. Concebida como una parodia crítica, no solo al régimen de Franco, sino también a los líderes políticos mundiales, fue rechazada por la prensa española y bien recibida en Iberoamérica. Con un juego doble de identidades, cervantinas por un lado, y políticas contemporáneas por otro, se desarrolla una de las obras del polígrafo, nunca después reeditada. Madariaga presenta una novela claramente cervantina en su escritura, en su estilo, como el propio título asegura: La más verídica que verdadera historia de Sanco Panco. Escribiola Miguel de Corzantes y la da hoy a luz Salvador de Madariaga, 
haciendo un guiño nada más empezar a la técnica del manuscrito hallado, que parodia Cervantes. Pero también presenta una voluntad completamente contemporánea, al tratar los asuntos y personajes más relevantes de la política mundial, sin nombrarlos directamente. Así, en este trabajo intentaré ofrecer el juego del autor para recrear la escritura cervantina, especialmente el Quijote, jugando con las identidades, quijotescas y contemporáneas, para poder analizar las intenciones de su autor y el valor narrativo de esta pericia técnica. Asimismo, pretendo situar a Madariaga en el puesto que reclama en la historia de la literatura española, no solo como erudito cervantista, sino como escritor capaz de aprovechar y llevar a cabo proyectos coherentes de creación literaria.

Palabras clave: Miguel de Cervantes, Salvador de Madariaga, Don Quijote de la Mancha, rescritura.

Title: Cervantine writing in Sanco Panco; parody and recreation of the Quijote by Salvador de Madariaga.

\section{Summary:}

Salvador de Madariaga's novel Sanco Panco was published in 1964 by the Mexican publishing house Latino Americana. Conceived as a critical parody, not only of Franco's regime but also of the world's political leaders, it was rejected by the Spanish press and well received in Latin America. With a double play of identities, Cervantines on the one hand and contemporary politics on the other, flows one of the works of the scholar, never again reprinted. Madariaga presents a novel that is clearly Cervantine in its writing, its style, as its own title asserts: La más verídica que verdadera historia de Sanco Panco. Escribiola Miguel de Corzantes y la da hoy a luz Salvador de Madariaga, giving at the very beginning a wink to the technique of the manuscript discovered that Cervantes parodies. But he also presents a completely contemporary will, dealing with the most relevant matters and personages of the world's politics without directly naming them.

Therefore, in this work, I will try to offer the play of the author to recreate the Cervantine writing, specially the Quijote, playing with the identities, quixotic and contemporary, to be able to analyse the intentions of the author and the narrative value of this technical expertise. Moreover, I intend to place Madariaga in the position that he deserves in the history of the Spanish literature, not only as a Cervantes knowledgeable scholar, but as a writer capable of making the most of and executing consisting projects of literary creation.

Key-words: Miguel de Cervantes, Salvador de Madariaga, Don Quijote de la Mancha, rewriting. 